\title{
Como é Ser Adolescente do Sexo Feminino na Periferia?
}

How is it to be a female adolescent in the suburb?
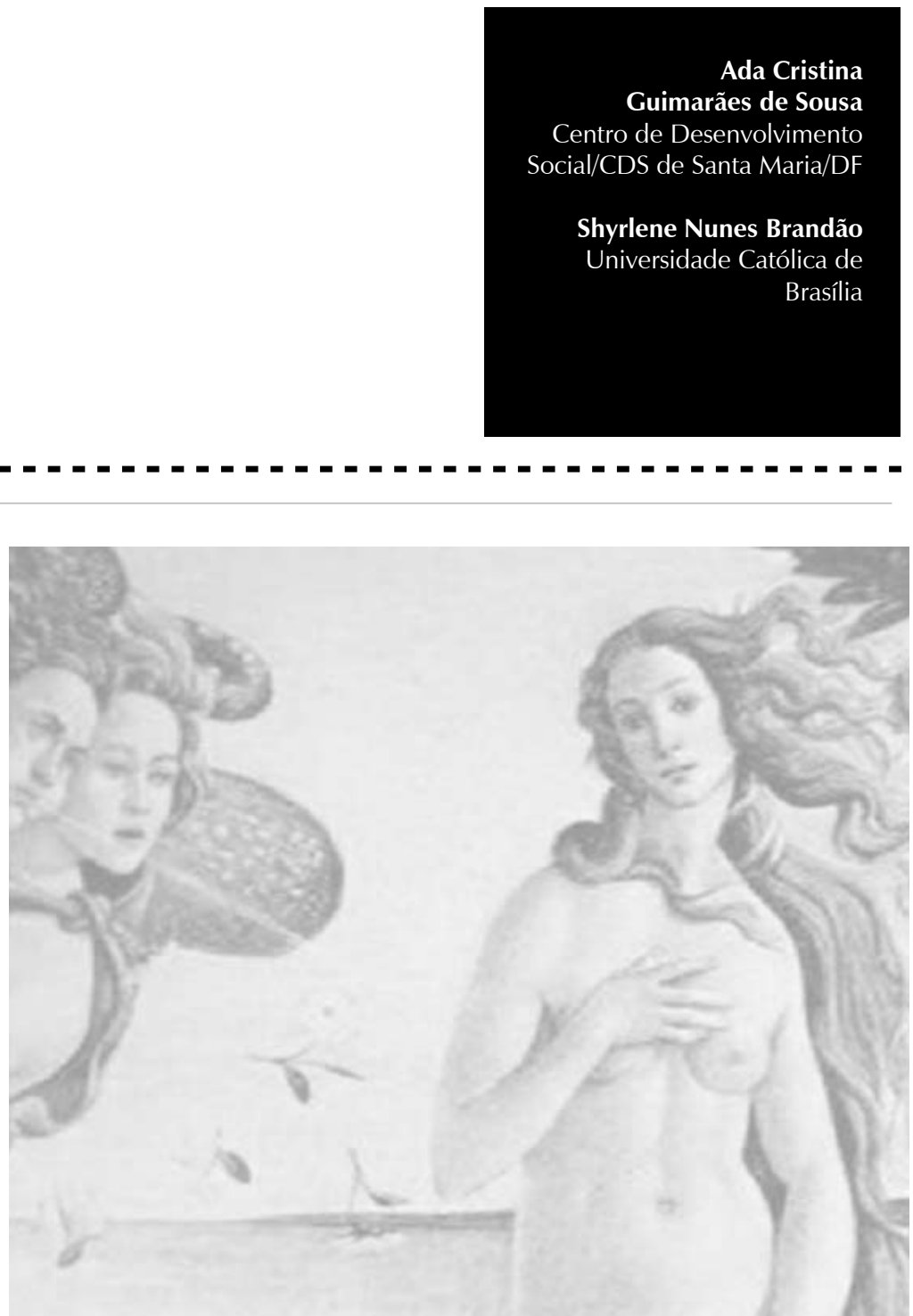
Resumo: Esse artigo apresenta uma pesquisa qualitativa realizada com três adolescentes do sexo feminino residentes na periferia de Brasília. O objetivo foi compreender o processo de construção da identidade feminina das participantes. A coleta de dados foi realizada por meio da técnica de grupo focal, da aplicação do recurso de colagem e de duas entrevistas individuais e semi-estruturadas. A análise de conteúdo possibilitou compreender que as identidades de gênero e classe social estão articuladas. Tais resultados estão de acordo com os estudos culturais de Stuart Hall e a perspectiva da Psicologia sociohistórica, que serviram como base teórica para a investigação.

Palavras-chave: Identidade. Adolescentes. Gênero. Periferia.

Abstract: This article presents a qualitative research developed with three female teenagers who live in the suburb of Brasilia. The objective was the comprehension of the process of female identity constitution of the participants. Data was collected through the focal group methodology, the application of collage resource and two single semi-structured interviews. The content analysis allowed to understand that gender identities and social class are articulated. These results are in accordance with the studies of Stuart Hall and the perspective of the sociohistorical Psychology, which were considered the theoretical bases for the study.

Keywords: Identity. Adolescents. Gender. Suburb.

Este texto relata um estudo qualitativo realizado com três adolescentes de Santa Maria/DF, cidade da periferia do Distrito Federal, e que teve como objetivo conhecer a identidade feminina e a identidade de moradora de periferia das participantes. Primeiramente, apresentamos os conceitos de identidade e adolescência em uma concepção crítica e segundo a identidade local. Em seguida, são apresentados a metodologia utilizada e os resultados, obtidos da análise de conteúdo e organizados em três eixos maiores que apresentam subtópicos. Os resultados revelam que a identidade de adolescente moradora de periferia é fortemente marcada por questões de gênero, relacionadas às condições sociais do contexto em que as adolescentes estão inseridas.

\section{O conceito de identidade na Psicologia social}

A Psicologia sociohistórica compreende que o indivíduo recebe influências sociais na sua identidade, ao mesmo tempo em que contribui para as transformações no tempo e na História. Segundo essa concepção, é no contexto que o indivíduo se integra, é integrado e se movimenta, o que possibilita mudanças e transformações em sua identidade. De acordo com Jacques (1998), o indivíduo é personagem, e, simultaneamente, autor-personagem de uma história construída por si mesmo. É um processo dialético, de movimento e de construção psicossocial.

Ciampa (1987) afirma que a identidade é metamorfose, movimento. Destaca que a nossa identidade é constituída a partir das diferenças e semelhanças que se apresentam de acordo com os vários grupos sociais dos quais fazemos parte. A partir da identificação com os grupos, a identidade social é constituída e recebe predicativos mais específicos, como identidade étnica, religiosa e de gênero, por exemplo. A diferenciação possibilita a emergência da identidade pessoal, que inclui as características psicológicas, físicas e a história de vida de uma pessoa.

Alguns autores compreendem identidade como imagem, representação e conceito de si. São expressões que estão relacionadas 
A identidade não se dirige apenas aos aspectos representacionais mas também aos aspectos relacionais, porém existem as possibilidades de vivenciar as identidades que ainda não foram descobertas. aos sentimentos, aos pensamentos que o indivíduo tem de si mesmo.

A identidade não se dirige apenas aos aspectos representacionais mas também aos aspectos relacionais, porém existem as possibilidades de vivenciar as identidades que ainda não foram descobertas. Esta é uma das maiores contribuições da Psicologia social sociohistórica: compreender que o processo de identidade não é fechado, mas pleno de possibilidades, desdobramentos e articulações entre os diversos e diferentes tipos de identidade.

A categoria identidade também é estudada nas diferentes ciências sociais; entre elas, destacam-se os estudos sociais e culturais, que apontam a complexidade, a metamorfose da identidade, ou melhor, das identidades, do ponto de vista das transformações socioculturais e, principalmente, econômicas, da pós-modernidade.

Segundo Hall (2000), as velhas identidades, estáveis e únicas, que estabilizaram o mundo social, estão em declínio; novas identidades surgem e fragmentam o indivíduo moderno, por muito tempo visto como possuidor de uma única identidade cultural. Esse autor enfatiza que o processo de identificação, através do qual nos projetamos em nossas identidades culturais, produz o sujeito pósmoderno e concebe-o não como dotado de uma identidade fixa, única ou permanente. O sujeito assume identidades diferentes em momentos distintos, identidades que não são unificadas ao redor do "eu" coerente. Essa concepção dos estudos culturais é congruente com o conceito defendido pela Psicologia social.

Sob essa perspectiva, a identidade é um processo dinâmico e articulado, não uma totalidade, unificada e delimitada. Isso se reflete na sociedade construída pelos sujeitos pós-modernos, que são seres dinâmicos, complexos e em constante metamorfose. O processo é algo parcial: a estrutura da identidade permanece aberta, fragmentada e inacabada.

As contribuições dos estudos culturais permitem entender que a identidade feminina, a identidade adolescente e as identidades locais (periferia, comunidade) podem ser articuladas. Logo, não é a identidade, mas são as identidades. Neste estudo, o objetivo é conhecer a construção da identidade feminina em adolescentes da periferia e destacar a articulação da identidade feminina com a identidade da periferia.

\section{A concepção crítica da adolescência articulada com a identidade da adolescente moradora de periferia}

O conceito de adolescência tem sido bastante discutido nas teorias do desenvolvimento e na Psicologia em geral. Alguns teóricos vêem o fenômeno como universal e previsível. A concepção aqui apresentada enfoca a existência de diferentes tipos de adolescência, por tratar-se de indivíduos inseridos em contextos socioculturais diferentes.

Ozella (2002) critica Erickson pelo fato de este institucionalizar a adolescência como fase especial no processo de desenvolvimento e ter introduzido o conceito de moratória, identificando essa fase como de confusão de papéis, de crise de identidade e como período de transição entre infância e vida adulta. Destaca ainda que as definições anteriores não consideram a adolescência como algo criado ao longo da História enquanto fato social e psicológico, com significados na cultura e na linguagem que permeiam as relações sociais. Concordamos com a perspectiva de que a adolescência não é um período natural do desenvolvimento, mas um momento cujo significado e interpretação 
são dados pelo ser humano. Logo, nessa concepção, a adolescência seria constituída a partir das necessidades sociais, econômicas e das características que se estabelecem no processo, ou seja, acredita-se que existam diferentes tipos de adolescência. Como é ser adolescente do sexo feminino e morar na periferia?

\section{A identidade de moradora de periferia}

No Dicionário da Língua Portuguesa, a palavra periferia é definida como "o conjunto dos bairros mais afastados da zona central de uma cidade; subúrbio" (Dias, 1992). Essa definição, no entanto, mostra-se insuficiente para retratar as significações que acompanham o termo periferia, assim como favela, conforme discutido no estudo sobre políticas de identidades de jovens de uma favela realizada por Guareschi et al. (2003). Atribuímos o sentido de favela à palavra periferia, pois as favelas têm características semelhantes aos bairros periféricos.

As representações sociais sobre a favela e a periferia e sobre quem mora nesses lugares geralmente têm significados depreciativos, pois é feita uma associação (estigmatizada) da falta de estrutura física à conduta, ao modo de ser de quem habita na favela e na periferia e às características desses lugares. Como afirma Guareschi et al. (2003), para pesquisar tais comunidades, é importante visitá-las sem idéias pré-concebidas; desse modo, buscamos compreender os sentidos e os significados dados ao contexto social pelos moradores.

No estudo citado, verificou-se que os sentidos de viver na periferia muitas vezes são compreendidos como viver excluído da sociedade e não se considerar e ser considerado cidadão. A maioria dos bairros periféricos tem como características a falta de saneamento básico, dificuldade de meios de transporte, alto índice de desemprego e baixo nível de escolaridade, entre outros aspectos. Resumindo, os indivíduos das comunidades periféricas têm pouco acesso aos direitos básicos de cidadania, devido à má distribuição de renda e ao descaso das autoridades e da sociedade.

Os estudos culturais colaboram para a compreensão da construção das identidades, sendo que a(s) identidade(s) se desenvolve(m) em um contexto sociocultural, nos espaços onde as pessoas moram, dentro e fora da comunidade. "Os contextos existem como campos de cultura que produzem significados específicos para aqueles que criam, transformam e neles vivem" (Guareschi et al., 2003, p. 133).

Os autores verificaram que ser favelado(a) pode ter um significado negativo na identidade dos jovens, pois morar em um lugar sujo, distante, com poucos recursos físicos, materiais e poucas qualificações profissionais influencia o modo como se percebem e são percebidos pelas outras classes econômicas. Chaves (2001) também verificou que os adolescentes de classes populares consideram o estudo e o trabalho formas de ascensão social e de transformação da identidade social. Enfim, ser cidadão é ser reconhecido como tal.

Laclau, citado por Hall (2000), ressalta que a sociedade moderna é caracterizada pela diferença, permeada por divisões eantagonismos sociais, e que a identidade local é o espaço no qual a identidade se constrói. No entanto, de acordo com os estudos de Guareschi et al. (2003), se essas diferenças étnicas, culturais, de gênero e classe social são tidas como excluídas na pós-modernidade, tal fato pode trazer complicações para as identidades que estão "fora" dos padrões sociais, culturais e econômicos, por isso, faz-se necessário contextualizar essa(s) identidade(s). 
A pesquisa qualitativa enfoca a subjetividade, a construção teórica e o diálogo do pesquisador com o sujeito pesquisado, e preocupa-se com a qualidade das informações, a qualidade das relações; não concebe o pesquisador como neutro, mas como ser humano inserido em uma cultura, com pensamentos e sentimentos.

\section{Metodologia}

A pesquisa qualitativa enfoca a subjetividade, a construção teórica e o diálogo do pesquisador com o sujeito pesquisado, e preocupa-se com a qualidade das informações, a qualidade das relações; não concebe o pesquisador como neutro, mas como ser humano inserido em uma cultura, com pensamentos e sentimentos. Para Gonzalez Rey (2002), a construção da informação na pesquisa qualitativa não se apóia na coleta de dados, como se faz nas pesquisas tradicionais, mas segue um processo de construção e interpretação que acontece em todos os momentos da pesquisa.

Esta pesquisa tem como base o enfoque qualitativo que busca compreender o processo de investigação como algo construído pelo participante e pelo pesquisador. Portanto, a subjetividade de ambos faz parte da construção do saber, e ainda possibilita questionamentos sobre o que foi construído mutuamente.

Participantes: Três adolescentes, que moravam e cursavam o ensino médio em uma cidade de Brasília, e que são aqui apresentadas por nomes fictícios. Luana tinha 16 anos na época da pesquisa, cursava o segundo ano do ensino médio, os pais eram separados, e morava em casa própria com a mãe e uma irmã adolescente, que estava grávida. Fabíola tinha 17 anos, cursava o segundo ano do segundo grau, seus pais também eram separados, e morava com a mãe e dois irmãos pré-adolescentes em casa alugada. A mãe trabalhava como empregada doméstica. Vanessa tinha 17 anos, cursava o terceiro ano do ensino médio e morava com os pais e uma irmã em casa própria.

Instrumentos: Foi utilizado um encontro com grupo focal, pois, segundo Bauer e Gaskell (2002), essa técnica tem como objetivo estimular a fala dos participantes e provocar algumas discussões por meio de questões direcionadas a todos. Em grupo, ocorre maior interação social do que em uma entrevista individual, pois os sentidos ou representações que surgem são influenciados pelo caráter social da interação grupal. Para melhor compreensão e análise das informações, aplicou-se o recurso de colagem. Após o encontro com grupo focal, foram realizadas duas entrevistas semi-estruturadas e individuais para aprofundamento do tema.

Procedimento de coleta e análise dos dados: Foi realizado um contato com a Gerência Regional de Ensino-GRE e com uma escola de ensino médio da cidade de Santa Maria/ DF. A proposta foi apresentada em três turmas, sendo que dezoito adolescentes se interessaram em participar, e tiveram seus nomes e telefones anotados para contato posterior. O primeiro encontro foi marcado com metade das interessadas, e somente Fabíola compareceu. Novos contatos foram realizados com as outras nove adolescentes. No dia marcado, somente três adolescentes compareceram, inclusive Fabíola.

O encontro com grupo focal teve a duração de duas horas, e foi realizado em um centro comunitário da cidade. No grupo, foram lançadas questões orientadas por um roteiro que tinha como foco o tema Ser adolescente do sexo feminino na periferia; no entanto, a pesquisadora não ficou presa ao roteiro, mas explorou os temas que as adolescentes apresentavam. O recurso de colagem foi aplicado para facilitar a integração das participantes com a pesquisadora e entre si. No encontro em grupo, as adolescentes foram convidadas a participar de entrevistas individuais para aprofundamento do tema. Apenas Luana e Fabíola compareceram no dia combinado. Cada entrevista durou cerca de uma hora, foi gravada em fita k7 e transcrita posteriormente.

A técnica utilizada para analisar o material obtido foi a análise de conteúdo temática, 
conceituada por Turato (2003) como a mais simples das análises de conteúdo. A análise e a interpretação se deram por meio da categorização e subcategorização, e formaram os eixos temáticos que foram construídos a partir das leituras flutuantes. O levantamento dos temas seguiu os critérios de repetição e relevância, e os significados expressos por meio das colagens foram agrupados aos significados das falas das participantes.

\section{Resultados e discussão}

A discussão e a apresentação dos resultados são caracterizadas por meio dos seguintes eixos temáticos e suas subcategorias, que, apesar de apresentados separadamente, apresentam forte interligação:

1) As relações eu - outro: construção e metamorfose; 1.1) relações grupos de pares e 1.2) espaço para falar de si e ficar sozinha; 2) gênero: entre a crítica, a reprodução e a mudança; 2.1) ser mulher: poder ou submissão?; 2.2) trabalho doméstico e 2.3) naturalizações de gênero; 3) identidade da adolescente de periferia articulada com a identidade feminina; 3.1 ) vivência da realidade social e 3.2.) ascensão social e mobilização social.

1. Relações eu - outro: construção e metamorfoses na identidade feminina

Essa categoria relata como as relações com o outro colaboram para a construção da identidade das adolescentes e abarca subcategorias que apresentam a importância do grupo de pares na construção das identidades das adolescentes. A última subcategoria revela que as adolescentes têm necessidade de ficar sozinhas e de ter um espaço para internalizar os significados dessas relações sociais.

$\mathrm{Na}$ adolescência, o sujeito amplia suas relações sociais por meio do grupo de pares.
A relação com o grupo é uma das mais presentes e significativas nesse momento da vida, no qual novas formas de se relacionar com o corpo em transformação, com a sexualidade e com o outro são construídas. Segundo Lane (1989), é no contexto grupal que a pessoa se identifica com o outro e, ao mesmo tempo, se diferencia, construindo assim sua identidade.

De acordo com Ciampa (1984), a identidade é formada a partir do momento em que o indivíduo se diferencia do outro, se aproxima e se identifica com esse outro, o que podemos verificar na seguinte afirmação: “(...) Todo mundo tem que viver em grupo, se eu não conviver com ninguém, vou ficar com a mente poluída, vou falar com a parede, a parede não vai falar nada. (...) Umas pessoas admiram, e outras não. 'Ah! A Luana é legal'; outras: 'Ah! A Luana é muito chata.'" (Luana).

\section{1 - Relações com o grupo de pares}

As adolescentes, em suas vivências com o grupo de pares, absorvem novos conhecimentos e aprendizados sobre os outros, as relações sociais e a relação consigo mesmas, ou seja, por meio desse contato, as possibilidades de atuação social são desenvolvidas e ampliadas. Dentro do grupo, dividem experiências, trocam afetos, criam novos laços afetivos e constroem suas identidades.

A amizade é caracterizada como algo importante pelas participantes. No grupo de pares, sentem-se aceitas e iguais, e, ao mesmo tempo, únicas e diferentes, como vemos na seguinte fala: "Quando a gente quer falar uma coisa, fala sem medo. É sincera umas com as outras; a gente gosta de festa, de namorar, conversar e de reunião. (...) Somos unidas, quando uma chora, todo mundo chora; quando uma briga, todo mundo briga; quando uma precisa de uma coisa, as outras correm atrás." (Luana). 
"Na escola, a gente conversa, tipo assim, a vida ali; a pessoa pensa que é só curtição beber, fumar. Um dia, para minha colega, falei: 'Moça, a vida não é só curtição, não'. Aí ela: 'que tem que aproveitar enquanto é nova, depois que for velha, já era, acabou'. Ela fica pensando no que é agora, mas no futuro elas não tão nem aí, minhas amigas".

Fabíola.
As adolescentes aprendem a se diferenciar do outro no grupo de pares, o que significa não ceder às pressões que o grupo faz sobre os membros, assim como aprendem a defender suas idéias e atitudes dentro e fora do grupo de pares:"Na escola, a gente conversa, tipo assim, a vida ali; a pessoa pensa que é só curtição beber, fumar. Um dia, para minha colega, falei: 'Moça, a vida não é só curtição, não'. Aí ela: 'que tem que aproveitar enquanto é nova, depois que for velha, já era, acabou'. Ela fica pensando no que é agora, mas no futuro elas não tão nem aí, minhas amigas." (Fabíola).

Muitas vezes, esse processo de escolhas e opiniões é conflituoso, pois nem sempre o(a) adolescente consegue se posicionar de forma diferente dentro do grupo, o que traz sofrimento e arrependimento, como foi percebido em alguns momentos da discussão do grupo focal.

\section{2- Espaço para ser, falar de si e ficar sozinha}

Essa subcategoria surgiu das falas que enfatizaram a necessidade de um espaço para expressarem suas vivências como adolescentes do sexo feminino. É no espaço para falar de si que elas revelam quem são. A partir da fala no meio social, as jovens demarcam suas identidades para si e para os outros, assim como as transformações que ocorrem em suas vidas. As participantes enfatizaram a necessidade de um espaço (físico e/ou simbólico) para exercerem o "eu", para refletir, que possibilitasse trocas de pensamentos e sentimentos.

Acreditamos que identificaram, no grupo focal e nas entrevistas individuais, a abertura de um espaço que aceitou o jeito de ser de cada uma. Destacamos que essa escuta acadêmica não faz parte do cotidiano da periferia, e ainda, tratando-se de um grupo de adolescentes do sexo feminino, foi algo novo na vida das adolescentes, fator que pode ter contribuído para a coleta de dados.
Esse espaço físico extrapola o espaço da pesquisa, que aponta a casa, a escola e o grupo de pares, entre outros, como os fatores que proporcionam o espaço simbólico para ser e para vir a ser adolescente/mulher. É no espaço para ficar sozinha e para falar de si que as transformações e as metamorfoses também acontecem. No grupo, as adolescentes falaram sobre a necessidade de privacidade, de liberdade e de um lugar para ficarem sozinhas, o que também foi representado nas colagens: "Coloquei aqui que cada pessoa tem que ter seu canto para pensar, chorar, ver o que fez de errado, se cada pessoa tiver seu canto e sua liberdade (...), um canto para fazer o que quiser nele". (Luana, sobre figura de um quarto). " $E$ aqui é um lugar para memorizar as coisas e descansar. Memorizar as coisas que estão se passando, acho que é bom." (Vanessa, sobre figura ao ar livre).

As participantes sentem necessidade de ficar sozinhas para pensar nas vivências e em si mesmas, ou seja, existe uma tentativa de equilíbrio entre os momentos com o grupo, os momentos com a família e os momentos de solidão, o que pode ser compreendido como uma necessidade de dar espaço para o eu em metamorfose.

É nesse espaço que elas pensam sobre suas atitudes e elaboram sentimentos sobre a relação eu-outro, refletem e tomam decisões e colocam em prática o papel de autoras sociais, desenvolvendo-se como pessoas: “(...) A gente conversou com nossa amiga, ela deu uns conselhos, aí tem que parar para pensar. Se tô errando muito com namorado, amigo, ela vai lá e fala: 'você tem que parar para pensar um pouco'. Depois você vai lá e age (...). A gente guarda todos os conselhos para ver qual é o certo; se tiver tudo certo, a gente vai e segue; se não tiver, aquilo segue sua mente." (Fabíola).

Percebe-se o exercício de autonomia no sentido de ser dona de sua vida e de seu 
"Ah! Homem, a partir dos 14 anos, tem sua própria liberdade, pode sair. Fala: 'mãe vou sair'; ele não fala: 'mãe, posso sair?' Já com a menina: 'Não pode sair por causa disso e disso'. Menino: 'mãe, vou sair', e já saiu, pronto, chega na hora que quiser, faz o que quiser, não pode reclamar, porque menino tem aquela coisa assim: 'Ah eu sou homem, você é mulher, posso fazer, você não pode'. Às vezes dá vontade de ser menino, por causa disso". Luana corpo, com o aumento das responsabilidades e a consciência do eu. A necessidade de pensar nas ações interfere na preocupação com as conseqüências das ações tomadas anteriormente. Essa fala confirma a concepção de sujeito ator social no contexto sociohistórico. A necessidade de um espaço para falar de si foi percebida no grupo focal, pois as adolescentes estavam ansiosas para falar e encontraram no grupo de pesquisa um lugar onde puderam desabafar: “(...) Estou gostando de falar essas coisas, eu gosto de ficar falando (risos). Igual estava conversando com a Luana, que eu tô gostando muito; pra mim, não podia acabar". (Fabíola). "Foi bom, a gente tipo desabafa o que a gente sente, $o$ que acha das coisas. Nem tudo pode falar para a amiga, para a mãe, e às vezes a gente fala para a amiga e ela fala para alguém, mãe tipo fala pra pai. Aífica chato, né? Às vezes é bom falar com uma pessoa que guarde segredo mesmo." (Luana).

O fato de ser adolescente e não ser ouvido(a) pelos adultos e pela sociedade é acrescentado ao fato de ser mulher e morar na periferia, o que talvez dificulte as expressões de sentimentos, de pensamentos e até mesmo da identidade feminina adolescente.

2- Gênero: entre a crítica, a reprodução e a mudança

A questão de gênero se fez presente em todos os eixos; por esse motivo, criou-se um eixo específico no qual se pudesse discutir as dimensões presentes na identidade das adolescentes.

De acordo com a historiadora Joan Scott (1990), a categoria gênero se refere à organização social da relação entre os sexos. As relações de poder entre os sexos serão sempre carregadas dos sentidos próprios de cada sociedade e de seu tempo. Essa compreensão também é adotada na Psicologia sociohistórica, e pode ser identificada nos relatos das participantes.

\section{1- Ser mulher: poder ou submissão?}

Ao longo das temáticas analisadas, percebese como o gênero e as suas implicações estão presentes na vida dessas adolescentes nas diversas relações estabelecidas. Essa categoria relaciona gênero a dois conceitos interligados: poder e dominação, e relata como isso é vivenciado por elas no dia a dia.

As relações de poder e dominação são compreendidas pelas teorias feministas e socio-históricas como um dos aspectos que constituem a categoria gênero. No entanto, como ressalta Scott (1990), gênero não se refere somente ao sexo feminino, mas abrange os significados construídos socialmente do que é característico de cada sexo biológico, o que possibilita uma forma de dominação sobre os corpos e as mentes dos indivíduos. O que significa ser mulher para essas adolescentes? Por meio das falas das participantes, verificamos a presença de sentimentos de indignação, discriminação e revolta, conforme vemos a seguir: "Ah! Homem, a partir dos 14 anos, tem sua própria liberdade, pode sair. Fala: 'mãe vou sair'; ele não fala: 'mãe, posso sair?' Já com a menina: 'Não pode sair por causa disso e disso'. Menino: 'mãe, vou sair', e já saiu, pronto, chega na hora que quiser, faz o que quiser, não pode reclamar, porque menino tem aquela coisa assim: 'Ah eu sou homem, você é mulher, posso fazer, você não pode'. Às vezes dá vontade de ser menino, por causa disso." (Luana).

Na frase acima, a participante reproduz a fala de um menino e a fala de um adulto. Percebe-se que sua fala não aparece no diálogo representado; sua voz parece ser abafada pelas demais, e está oculta na representação da adolescente. A participante expressa o desejo de ser menino devido ao poder do sexo masculino na sociedade.

Esse diálogo revela como se dão as relações de gênero no cotidiano das adolescentes e, 
ainda, como se sentem oprimidas e se deixam oprimir por acreditar que não podem falar nada. Percebem que têm que pedir para sair, mas os meninos simplesmente saem sem autorização e não são reprimidos por isso.

Elas criticam as atitudes de poder e opressão, sendo que, em alguns momentos, cedem às regras sociais. As participantes não relataram de forma explícita se se sentem discriminadas no cotidiano, mas, de acordo com os relatos, nota-se uma constante discriminação/ opressão "naturalizada", que talvez dificulte a identificação desse tipo de situação, retratada na fala de Luana, a seguir, quando diz que é normal o pai mandar na filha: "Acho que pai é normal, mas já vivi situações de irmão, amigo, querer mandar: -' Quem é você para falar o que vou fazer?' - 'Ôxe, minha filha, estou fazendo isso para o seu bem'. -'Mas tá querendo mandar, você não é nem meu irmão..."'

As participantes percebem que existem diferenças sociais entre os sexos, e acreditam que têm os mesmos direitos que os homens. Admitem a existência de diferenças nas habilidades entre os sexos, mas afirmam que não é o sexo biológico que torna as mulheres inferiores aos homens. Declararam que existe discriminação contra o sexo feminino, mas parece não ser claro para as adolescentes que a ideologia de oposição entre os sexos faça parte de uma construção social.

\section{2- Trabalho doméstico}

Essa subcategoria se destacou pelos significados sociais atribuídos e tidos como papéis femininos na sociedade. A tradição de as atividades domésticas serem atribuídas ao gênero feminino, independentemente da classe social, foi o motivo que determinou o surgimento dessa discussão, sendo que o trabalho doméstico se relaciona com os demais temas.
Nos estudos sobre adolescentes pobres no Brasil, Madeira (1997) identificou que a ocupação das meninas dentro e/ou perto da casa decorre de três fatores: 1-ideológicos - relacionados à socialização das meninas pela família, que se recusa a liberar as meninas como uma forma de controlar sua sexualidade; 2- necessidade que a família tem do trabalho da menina no ambiente doméstico, no cuidado da casa e dos irmãos e ainda para ajudar a mãe no trabalho fora de casa; 3- a dificuldade da entrada da mulher no mercado de trabalho por outras profissões. Essa autora destacou a falta de oportunidades oferecidas aos adolescentes pobres, o que confirma o processo de exclusão vivido por essa população.

Nos relatos apresentados, o trabalho doméstico aparece como algo natural ao papel da mulher. As adolescentes criticaram o fato de os meninos não colaborarem com as atividades domésticas e de elas terem que reproduzir as atividades do lar enquanto as mães estão trabalhando, o que pode ser confirmado pela teoria. Enquanto as mães estão trabalhando, elas são as donas de casa e cuidam dos irmãos. Exercendo e antecipando a dupla jornada de trabalho da mulher, caracterizado como trabalho doméstico e trabalho remunerado, nesse caso, as adolescentes dividem seu tempo entre a casa e a escola, como enfatiza Luana: "No intervalo, fico conversando com as pessoas; em casa, vou almoçar, arrumar a casa, termino de fazer as coisas e vou fazer dever. Fim de semana, vou pras festas, lavo roupa. É natural, normal, tipo as meninas arruma a casa, tal. Os meninos não têm que fazer nada. Igual tem uma colega minha, fala assim: 'Tô cansada, faço tudo dentro de casa, sou a única menina, e meus irmãos não fazem nada. Eu arrumo, eles vêm e bagunça'". Desde cedo, as adolescentes vivenciam a diferença cultural entre os gêneros e a dupla jornada de trabalho das mulheres. Os estudos aparecem na frase como uma das últimas atividades do dia. 
"Você tem um irmão; aí minha

mãe diz: 'Vai lavar louça", e eu pergunto: 'Por que ele não vai?' Minha mãe diz: 'Ele não pode, ele é homem'. Eu falei: 'É homem, mas tem mão'. A mesma coisa com meu pai: 'Ele trabalhou o dia todo', e eu digo: 'Eu estudei'

(risos). Mulher tem que ficar no fogão e esfriar no tanque..."'

Luana
No cotidiano, as participantes exercem múltiplos papéis femininos e têm possibilidade de transformá-los ao longo do tempo e da História, como nos mostra o relato de Luana, abaixo:

"Você tem um irmão; aí minha mãe diz: 'Vai lavar louça', e eu pergunto: 'Por que ele não vai?' Minha mãe diz: 'Ele não pode, ele é homem'. Eu falei: 'É homem, mas tem mão'. A mesma coisa com meu pai: 'Ele trabalhou o dia todo', e eu digo: 'Eu estudei' (risos). Mulher tem que ficar no fogão e esfriar no tanque..."'

$\mathrm{Na}$ fala acima, a adolescente questiona a mãe porque o irmão e o pai não podem lavar louça, e a resposta da mãe reforça e mostra-se conivente com as diferenças sociais entre os sexos no ambiente familiar. Esse é um exemplo da influência da família no aprendizado e na reprodução de gênero na vida das adolescentes.

O fato de a mãe acreditar que o homem trabalha fora e, por esse motivo, não pode dividir as tarefas domésticas faz com que a adolescente reproduza o mesmo papel materno (trabalho e atividades domésticas), logo, a jovem divide seu tempo entre as tarefas escolares e domésticas. Como ainda não conquistou sua autonomia, vêse obrigada a ceder às regras familiares, reproduzindo o aprendizado de que as responsabilidades domésticas (o cuidado, o zelo, a maternidade) são papéis da menina/ mulher.

O trabalho doméstico feminino é tido como algo natural pela sociedade. Madeira (1997) destaca que o trabalho doméstico oculta o nível de desemprego entre as jovens da periferia, o que as caracteriza como "desempregadas ocultas", pois estão desempregadas e trabalham de forma oculta no limite da casa, escondidas, portanto, do mercado de trabalho formal.

\section{3 - Naturalizações de gênero}

Como são as representações do feminino e do masculino das adolescentes? Em que sentido essas representações influenciam suas identidades? De modo geral, as representações do feminino foram caracterizadas e relacionadas à beleza, delicadeza, fragilidade, cuidado, sensibilidade, força (com relação à figura materna) e indecisão/conflito. As representações do gênero masculino se referem às características como insensibilidade, imaturidade, poder e determinação. Algumas representações, como beleza, vaidade e romantismo (sensibilidade), também foram percebidas nas colagens: "Homem às vezes tem mais cabeça do que mulher. 'Eu tenho mais responsabilidade que você (...)' Vem aquele negócio de machismo: 'Eu sou homem, sei me cuidar'- 'Ah, mas mulher também sabe se cuidar'. - 'Mas você é nova'. - 'Você também é'. - 'Não, sou homem', aquele negócio de machismo, mesmo. (...) Menina tem mais sentimento, são muito sentimentais, por qualquer coisa chora, fica se lamentando, coloca a culpa em tudo. Homem não tem esse negócio de ficar chorando, se lamentando, fez, e tá feito." (Luana). "Sei lá (risos). É sair, né, conversar com todo mundo, me arrumar, ter vaidade. Conversar sobre as coisas, assim. Mulher tem mais sentimentos do que os homens. É isso que eu acho." (Fabíola, sobre como é ser mulher).

Essas representações confirmam o fato de a categoria gênero influenciar na construção da identidade feminina de modo naturalizado para as adolescentes, que acreditam existir características específicas do sexo feminino e do sexo masculino. O fato de esperarem proteção do sexo masculino pode explicar porque se sentem frágeis diante do mesmo e vice-versa, ou seja, é devido a uma ideologia criada a favor do poder e do controle do masculino sobre o feminino que as adolescentes internalizaram como características femininas a fragilidade, a vaidade e a sensibilidade. 
A representação do feminino está articulada com a diversidade e com a possibilidade de atuação da mulher na sociedade,

mas, ao mesmo tempo, existe uma naturalização dos papéis femininos e masculinos.
Por outro lado, sobre o papel da mulher na sociedade, as adolescentes acreditam que está relacionado à ajuda, à conscientização social, ao cuidado e à solidariedade. Percebem a mulher com uma postura ativa, questionadora, mutante, que vai além dos limites da casa e que se expande para a comunidade, o mundo, a rua: "Meu papel? Acho que ajudar a comunidade. Acho que ajudar mais a comunidade. De forma geral, que a vida não é assim como as pessoas pensam." (Fabíola).

“(...) Pretendo ser advogada, por que tem assim, posso cobrar dinheiro e não posso. Tem umas pessoas que tão em uma enrascada porque colocaram, e não porque ela fez. Se ela não tiver condições, eu posso ajudar." (Luana).

A representação do feminino está articulada com a diversidade e com a possibilidade de atuação da mulher na sociedade, mas, ao mesmo tempo, existe uma naturalização dos papéis femininos e masculinos. No entanto, as adolescentes se colocam como ativas no contexto socio-histórico, buscando e almejando mudanças em si próprias e nos outros por meio da profissionalização.

3- A identidade da adolescente de periferia articulada com a identidade feminina

A concepção de que o processo da identidade é dialético, em constante movimento e transformação, é também compreendida por Hall (2000), que destaca que, no contexto da globalização, não existe uma identidade, mas várias identidades que podem ser articuladas entre si. Guareschi (2000) afirma que, dentro do cenário econômico, cultural e político da pós-modernidade, os processos de construção de identidades sociais e culturais estão sofrendo vários conflitos, especificamente nos grupos em que as identidades não são reconhecidas ou valorizadas socialmente; são, portanto, as identidades discriminadas pela elite. Este estudo abrange identidade local e identidade de gênero, e busca articulá-las.

A cidade de Santa Maria é caracterizada pelo fato de ser uma área periférica e fazer parte dos programas de assentamentos do Governo do Distrito Federal. As histórias das cidades do DF são fortemente marcadas por políticas sociais de caráter assistencialista: lotes foram doados pelo governo, e a maioria dos moradores recebe "benefícios", como cesta de alimentos e bolsa-escola, entre outros. A palavra periferia, que simboliza as comunidades e bairros afastados do centro, suscita representações sociais nas quais seus habitantes são associados às características físicas dos locais onde habitam. Como as adolescentes percebem suas identidades no contexto da periferia?

\section{1- Vivência da realidade social}

As vivências das adolescentes na comunidade revelaram sentimentos e situações de discriminação, insegurança, indignação e medo, além dos sentimentos de pertencimento e identificação com o estilo de vida e os valores das pessoas que ali vivem.

No primeiro contato com os adolescentes na escola, ao informar o título da pesquisa em uma das salas de aula, foi sugerido pelos alunos que a palavra periferia fosse substituída por cidade do DF. Pode-se pensar inicialmente em uma negação do fato de ser morador da periferia, mas isso pode ser explicado pelo significado depreciativo e carregado de estigmas sobre o que é a periferia, tanto para os moradores quanto para as pessoas que moram nas zonas centrais da cidade. Essas representações geram um sentimento de exclusão social e discriminação, como vemos a seguir:"Se eu for procurar um emprego, e falar: 'Sou de Santa Maria.' 'Lá tem só maloqueiro, todo mundo deve ser maloqueiro, que não sei o 
"Você conhece as pessoas de um jeito, aí vai para outro lugar, é de outro jeito. Ah! É diferente, tá tão acostumado com aquilo que nem liga para o outro. Tô acostumada com o jeito daquela pessoa, e quando vejo que outra pessoa tem outro jeito, fica esquisito. Tipo, te trata de um jeito esquisito."

Luana quê.' Se fosse procurar um emprego hoje, acho que nem passaria na entrevista. O modo de falar, aprendi lá. (...) O modo de andar, de vestir, também. Pra mim, acho que roupa mais curta, calça mais colada. Tipo assim, o modo de vestir é mostrar o corpo. Na escola, só vejo menina de sainha." (Fabíola).

Essa fala revela como a adolescente se sente discriminada por pessoas de outras classes quando informa que habita na periferia. Pode-se pensar que a discriminação gere um sentimento de inferioridade, pois a jovem acredita que esse seria o motivo pelo qual não seria selecionada em uma entrevista de emprego.

Fabíola acredita que existam algumas características que a identificam como moradora da periferia, como o modo de falar e de vestir, o que pode ser compreendido como sentimento de pertencimento à comunidade. Reconhece que isso faz parte da sua identidade adolescente, mas, ao mesmo tempo, são essas características que a diferenciam das adolescentes de classe média.

Com relação aos tipos de roupas, podese pensar na influência da mídia sobre a identidade feminina, em que o uso de roupas sensuais e a padronização do feminino são estimuladas pelo mercado consumista globalizado. De modo geral, a participante fala sobre sua identidade de adolescente da periferia e a discriminação que sofre com essa identidade, como assinala Guareschi (2000).

Os sentimentos de identificação e diferenciação no contexto social podem ser percebidos em: "Você conhece as pessoas de um jeito, aí vai para outro lugar, é de outro jeito. Ah! É diferente, tá tão acostumado com aquilo que nem liga para o outro. Tô acostumada com o jeito daquela pessoa, e quando vejo que outra pessoa tem outro jeito, fica esquisito. Tipo, te trata de um jeito esquisito." (Luana).

As adolescentes se sentem discriminadas em seus contatos com as pessoas que não moram na mesma cidade que elas. Revelam que se sentem excluídas. Os sentimentos de exclusão e discriminação permeiam as relações sociais dentro e fora da comunidade. Percebem que são diferentes das adolescentes de outras classes sociais e classificamnas de "patricinhas". Percebemos nesse momento a possível existência de uma coresponsabilidade na exclusão denunciada por elas, uma vez que a rotulação do outro também o mantém afastado, apesar de terem ressaltado na discussão do grupo focal a importância de se ter cuidado com as generalizações dessa rotulação.

Sobre o aspecto das relações eu-outro na periferia, as adolescentes destacaram que existem nas comunidades de classes sociais desfavorecidas sentimentos de união, amizade, solidariedade e comunidade, o que pode ser compreendido como fator de resiliência, ou seja, é uma das formas que as comunidades carentes desenvolveram para enfrentar a desigualdade e a exclusão social. Por outro lado, sentem-se inseguras por acreditarem que o fato de morarem na periferia e estudarem em escola pública seja obstáculo para o trabalho e para a entrada no ensino superior, não cogitando a universidade pública, o que pode ser relacionado à realidade social enfrentada por essas jovens e confirmado no artigo de Guareschi (2000) sobre a discriminação das identidades que não estão nos padrões socioeconômicos da globalização. Esse fato é acompanhado por um sentimento de inferioridade, que pode ser compreendido no contexto de exclusão vivenciado por essas jovens no cotidiano, como revelado na fala de Fabíola sobre o vestibular: "Fiquei sabendo que é muito difícil; agora, com as cotas, tá dando espaço para os negros e tirando as pessoas brancas; (...) somos 
irmãos perante Deus, acho que o pessoal nem pensa muito. Acho que por causa da cor. Estudaram a vida todinha em escola particular, dentro da faculdade, vai lá, faz tudo. Nós estamos estudando na escola pública, qual a nossa chance? Nenhuma." (Fabíola).

No cotidiano, as adolescentes convivem com a injustiça social, a violência física e psicológica, a discriminação, e, ainda, com a concepção da exclusão e da falta de oportunidades. Acreditam que o trabalho seja uma forma de mudar de vida, pois sentem-se inseguras quanto ao futuro na periferia, o que se confirma na fala a seguir: "Tem uns que pensam assim: 'Ah! Não tem emprego, vou roubar isso e aquilo.' Uma vez, meu colega: 'Não tem emprego, vou roubar.' Tipo assim, o lugar que saio só é lá. Vejo que tenho que erguer minhas mãos; se eu ficar naquele lugar, não vejo futuro para meus filhos, não." (Fabíola).

A adolescente enfatiza que, para haver transformação, é necessário sair do lugar onde mora. Parece não acreditar que possa haver mudanças e/ou possa ter ascensão social morando no mesmo lugar. Inclusive o seu desejo de ser professora de Sociologia expressa a vontade de provocar algumas mudanças. Existe uma preocupação com o futuro dos filhos, o medo de que eles pensem como seu amigo, que roubar é a única solução. O contato da adolescente com a violência pode ser um dos motivos para essa procupação.

As atitudes discriminatórias são concebidas como fatos que as fazem crer que o mundo desprivilegiado onde moram não as reconhece como cidadãs. No discurso da discriminação, está implícito o discurso de cidadania ou da sua falta. De acordo com Quintana e Arpini (2003), alguns autores têm destacado que as perspectivas sociais são, para jovens de grupos populares, cada vez mais empobrecidas. $\mathrm{O}$ universo de perspectivas é obscuro, o que influencia na representação que constroem de si mesmos e em suas identidades. Neste estudo, identificou-se certa insegurança sobre o futuro, mas, mesmo assim, relataram suas aspirações profissionais e desejos de mudança.

Podemos pensar que as perspectivas são empobrecidas devido à carência de investimentos sociais na periferia. Como ter perspectivas claras em um local que não oferece oportunidades e quando oferece, não são as oportunidades esperadas pelas jovens? Pode-se relacionar essa idéia com a conclusão de Giannechini et al. (2002), de que os adolescentes vêem a possibilidade de sair da periferia como o único modo de adquirir seus direitos e exercer sua cidadania, mas também expressam que o exercício da cidadania pode ser realizado na mobilização social, por meio das profissões escolhidas.

\section{2 - Ascensão social e mobilização social}

As perspectivas para o futuro envolvem o desejo de ascensão social, que pode ser alcançado por meio dos estudos e do trabalho. O trabalho aparece como algo preocupante, por se sentirem discriminadas pelo fato de morarem em uma cidade da periferia. Quais as perspectivas para o futuro? Estudar é percebido pelas jovens como meio para a profissionalização, e terminar o ensino médio significa dar o primeiro passo para a entrada no mercado de trabalho, o que está de acordo com os estudos de Alves (1997, citado por Ozella, 2002), em que os jovens trabalhadores vêem a escola e o trabalho como meios de alcançar autonomia.

O futuro é percebido como um desafio que depende de muito esforço pessoal e sucesso escolar. Nos relatos, verificamos a preocupação em colaborar com as despesas domésticas, o que pode ser verificado nos estudos de Domingues e Alvarenga (1997). As possibilidades de entrada no mercado 
O sentimento de justiça social é acompanhado pela perspectiva de mobilização social. As

adolescentes se vêem como transformadoras da realidade $e$ desejam realizar movimentos de mudança social. de trabalho são tidas pelas adolescentes de classes populares como forma de ascensão social: "Meu sonho é procurar um emprego, para comprar uma casa para minha mãe. $E$ de casar (...). Eu queria trabalhar fora, para ajudar minha mãe, para ter um dinheiro no banco, eu queria ser professora de Sociologia, mas é muito cara a faculdade (...)." Sobre a colagem que realizou: "Coloquei a história dessa mulher aqui, porque é meio parecida comigo, que ela não tem tudo." Conseguiu as coisas por causa do estudo dela, a mãe dela é doméstica." (Fabíola). "Eu quero fazer Medicina." (Vanessa).

As profissões aspiradas são socialmente valorizadas e tidas como profissões de elite (Direito e Medicina). Fabíola, no entanto, pretende cursar Sociologia, talvez tida pela mesma como via de conscientização e de mudança das injustiças sociais. $\mathrm{O}$ mesmo aparece nas falas da adolescente que sonha em cursar Direito. O fato de almejarem a entrada no mercado de trabalho por meio de profissões pode significar a busca de uma identidade social reconhecida socialmente, algo que sentem não acontecer em suas vidas.

O sentimento de justiça social é acompanhado pela perspectiva de mobilização social. As adolescentes se vêem como transformadoras da realidade e desejam realizar movimentos de mudança social. O desejo de ser professora de Sociologia pode significar a identificação com o professor de Sociologia e com a disciplina estudada, pelo fato de o professor também ser negro e, talvez, exemplo para a jovem: "Me sinto muito discriminada, pela cor e pelo cabelo. Tem gente que me trata assim que eu fico de cara. Ôxe (...) Por isso tenho vontade de ser professora de Sociologia por causa disso, tanta discriminação, nesse mundo, nunca vi." (Fabíola).

Os relatos estão de acordo com a reflexão de Chaves (2001), quando enfatiza que o adolescente pobre aspira ser, e não, ter. Nascimento (1999, citado por Chaves, 2000), acredita que o adolescente de classes abastadas, devido às suas inquietações à procura de mudanças, torna-se consumista; logo, as motivações da juventude para as mudanças são dirigidas para o consumo, enquanto o adolescente pobre se constrói como sujeito social de acordo com sua situação econômica e não é tão atraído pelos valores consumistas como o adolescente de classes sociais favorecidas.

No grupo focal, as adolescentes questionaram a participante Vanessa, que afirmou gostar de comprar roupas no shopping, e perguntaram por que ela não compra na feira, pois é mais barato. Esse fato pode ser compreendido como uma aceitação da realidade, na qual o poder de consumo é limitado pelas condições financeiras, sem tanta influência dos apelos consumistas como os jovens de classe média; conformam-se com as vestimentas que as caracterizam e as identificam como adolescentes de periferia, o que não quer dizer que não desejem ter tais vestimentas, adquirir a identidade cultural do(a) jovem pós-moderno(a) por meio de roupas de griffes.

\section{Considerações finais}

Como a pesquisa qualitativa postula que o(a) pesquisador(a) não é neutro(a) no processo de construção do conhecimento, é importante destacar que o tema faz parte da vida pessoal e profissional da primeira autora do texto, que é moradora de periferia. Foi essa vivência que a fez sentir e questionar o processo de transformação da adolescência nas meninas das comunidades desfavorecidas, verificar como esse processo ocorre nesse espaço e, ainda, quais são as perspectivas futuras dessas jovens.

O processo de identidade é algo complexo, que se metamorfoseia e se transforma 
no contexto sociocultural onde se dão as relações sociais. A identidade feminina se articula com outras identidades que são assumidas pelas adolescentes (classe social, periferia e raça).

As participantes da pesquisa logicamente estão envolvidas nessa complexidade da dialética da vida. Por esse motivo, é importante ressaltar que os resultados alcançados também estão inseridos no tempo e na História. Estudar o fenômeno da identidade exige um movimento de pesquisa contínuo, pois ele está em constante transformação. Os resultados mostram que as identidades das adolescentes são dialéticas, interagem entre si e com os sistemas (micro e macro). É um processo de constante construção e reconstrução do eu feminino.

Para compreender e lidar com adolescentes das classes populares, é necessário primeiramente conhecer sua realidade, seu cotidiano, suas falas e suas identidades em construção. Não se trata somente de adolescentes, mas de sujeitos que se relacionam e estão inseridos em sistemas simbólicos e construídos que permeiam suas identidades. Questionar os conceitos e processos da própria Psicologia faz parte da pesquisa qualitativa.

Como existem poucos programas sociais para jovens e raríssimos são direcionados para adolescentes do sexo feminino nas comunidades, podemos questionar qual a atitude das adolescentes quando surge um espaço no qual possam expressar suas subjetividades femininas. Seria estranhamento, medo ou vergonha? Inicialmente, dezoito jovens se dispuseram a participar da pesquisa, e talvez isso explique porque poucas adolescentes colaboraram, visto que as jovens não são estimuladas a pensar, a expressar suas vivências sobre gênero, classe social e adolescência. Falar e ser ouvido repercute na formação do eu e pode ser algo novo naquele contexto.
A abertura do espaço possibilitou a expressão de suas identidades (feminina, adolescente, periferia, étnica, local). A interação entre as pesquisadoras e as participantes proporcionou uma relação humana, espontânea, na qual a pesquisa e a profundidade das falas foram tão importantes quanto o contato e a relação que construímos. Conhecê-las foi conhecer de perto a emoção de ser adolescente na periferia.

O trabalho de pesquisa contribuiu também para a construção da identidade feminina da primeira autora deste texto, no sentido de ampliar o seu olhar de pesquisadora, mulher e atriz social. É importante refletir sobre o fato de que o pensamento não é algo distinto por sexo biológico, portanto, não pertence somente ao mundo masculino. O pensar não é separado do sentir, o que faz compreender que ser humano é simplesmente ser, e, ao mesmo tempo e complexamente, existir. $\mathrm{O}$ processo de pesquisa envolve sentimento, pensamento e sensação. E esse é um dos sentidos da Psicologia.

Os resultados revelam que as adolescentes da periferia sentem na pele a tripla discriminação pelo fato de serem do sexo feminino, adolescentes e moradoras da periferia. As participantes revelaram o desejo de transformar suas identidades por meio do trabalho, do estudo e da mobilização social. Percebem que são capazes de transformar suas identidades (gênero e classe social) ao longo do tempo e da História, e que existem algumas dificuldades no processo de construção, como a dificuldade de ingressar em uma universidade pública e arrumar um emprego. Deve-se observar que a identidade de periferia é constituída por um desejo de mobilidade social, de solidariedade para com as pessoas da comunidade, no sentido de prevenção.

A realização da pesquisa contribui para futuras intervenções com esse público-alvo e ainda para a criação de políticas públicas 
para a juventude. A sociedade atualmente se depara com um grande número de adolescentes grávidas, mas são poucas as ações que trabalham com a concepção do gênero na sexualidade feminina, ou seja, não são discutidas com a juventude questões de gênero, de dominação e de exclusão social.

Precisamos ouvir e perceber os sintomas psicossociais dos jovens da periferia e possibilitar que eles existam e se transformem, a fim de que possam ir além dos rótulos, ideologias e representações sociais. São sujeitos ativos, pensantes e cidadãos de direitos. Trabalhar com as adolescentes pode minimizar alguns desses problemas, pois, como mulheres, também exercem os papéis de maternidade, zelo e educação, entre outros. Um país que respeita os direitos dos jovens e das mulheres é um país que se preocupa com o futuro e com a vida.

\section{Ada Cristina Guimarães de Sousa}

Psicóloga do Centro de Desenvolvimento Social (CDS) de Santa Maria-DF.

E-mail: rhanana@hotmail.com

\section{Shyrlene Nunes Brandão}

Psicóloga, Mestre em Psicologia clínica pela Universidade de Brasília (UNB), professora da Universidade

Católica de Brasília (UCB).

E-mail: shylbrandao@terra.com.br

Endereço para correspondência:

Qr. 301, Conjunto F, Casa 4 Cep: 72501-506, Santa Maria-DF

\section{Referências}

Bauer, W., \& Gaskell, G. (2002). Pesquisa qualitativa com texto, imagem e som: um manual prático. Petrópolis, RJ: Vozes.

Chaves, E. S. (2001). Significações atribuídas ao cotidiano pelo adolescente pobre. Revista Brasileira de Crescimento e Desenvolvimento Humano, 11(1), 71-85.

Ciampa, A. C. (1984). Identidade. In S. T. Lane \& W. Codo (Eds), Psicologia social: o homem em movimento (pp. 58-75). São Paulo: Brasiliense.

Ciampa, A. C. (1987). A estória do Severino e a história da Severina: um ensaio da psicologia social. São Paulo: Brasiliense.

Dias, F. C. S. (1992). Dicionário da língua portuguesa-Larousse Cultural. São Paulo: Editora Universo.

Domingues, C. M. A. S., \& Alvarenga, A. T. (1997). Identidade e sexualidade no discurso adolescente. Revista Brasileira de Crescimento e Desenvolvimento Humano, 7(2), 32-68.

Giannechini, L. G., Oliveira, F. P., Comunello, L. N., Pacheco, M. L., Nardini, M., \& Guareschi, N. M. F. (2002). As relações raciais na construção das identidades. Psicologia em Estudo, Maringá, 7(2), 55-64.

Gonzalez Rey, F. (2002). Pesquisa qualitativa em psicologia. Caminhos e desafios. São Paulo: Pioneira Thomson Leaming.

Guareschi, N. M. F. (2000). Políticas de identidade: novos enfoques e novos desafios para a psicologia social. Psicologia \& Sociedade, $12,110-124$.

Guareschi, N. M. F., Oliveira, F. P., Giannechini, L. G., Comunello, L. N., Pacheco, M. L., \& Nardini, M. (2003). O cotidiano de meninos e meninas na favela: problematizando as políticas de identidade. In N. M. F. Guareschi \& M. E. Bruschi (Orgs.), Psicologia social nos estudos culturais: perspectivas e desafios para uma nova psicologia social (pp. 129-158). Petrópolis, RJ: Vozes.

Hall, S. (2000). Identidade cultural na pós-modernidade. Rio de Janeiro: D\&A Editora.

Jacques, M. G. C. (1998). Identidade. In M. G. C. Jacques, M. N. Strey, M. G. Bernardes, P. A. Guareschi, S. A. Carlos, \& T. M. G. Fonseca (Eds), Psicologia social contemporânea (pp. 159-167). Petrópolis, RJ: Vozes.

Lane, S. M. (1989). Psicologia social: o homem em movimento. São Paulo: Brasiliense.

Madeira, F. R. (1997). Quem mandou nascer mulher? Estudos sobre crianças e adolescentes pobres no Brasil. Rio de janeiro: Record; Rosa dos Tempos.

Ozella, S. (2002). Adolescência: uma perspectiva crítica. In M. L. J. Conúni, S. H. Koller, \& M. N. S. Barros (Orgs.), Adolescência e psicologia: concepções, práticas e reflexões críticas (pp. 16-24). Brasília: Conselho Federal de Psicologia.

Quintana, A. M., \& Arpini, D. M. (2003). Identidade, família e relações sociais em adolescentes de grupos populares. Estudos de Psicologia, Campinas, 20(1), 27-36.

Scott, J. (1990). Gênero: uma categoria útil de análise histórica. Educação e Realidade, Porto Alegre, 16(2), 5-22.

Turato, E. R. (2003). Tratado da metodologia da pesquisa clínica qualitativa. construção teórico-epistemológica, discussão comparada e aplicação nas áreas da saúde e humanas. Petrópolis, RJ: Vozes 